\title{
Access to affordable medicines and diagnostic tests for asthma and COPD in sub Saharan Africa: the Ugandan perspective
}

Davis Kibirige ${ }^{1,2^{*}}$, Leaticia Kampiire ${ }^{3}$, David Atuhe ${ }^{4}$, Raymond Mwebaze ${ }^{5}$, Winceslaus Katagira ${ }^{6}$, Winters Muttamba ${ }^{6}$, Rebecca Nantanda ${ }^{6,7}$, William Worodria ${ }^{8}$ and Bruce Kirenga ${ }^{6,8}$

\begin{abstract}
Background: Equitable access to affordable medicines and diagnostic tests is an integral component of optimal clinical care of patients with asthma and chronic obstructive pulmonary disease (COPD). In Uganda, we lack contemporary data about the availability, cost and affordability of medicines and diagnostic tests essential in asthma and COPD management.

Methods: Data on the availability, cost and affordability of 17 medicines and 2 diagnostic tests essential in asthma and COPD management were collected from 22 public hospitals, 23 private and 85 private pharmacies. The percentage of the available medicines and diagnostic tests, the median retail price of the lowest priced generic brand and affordability in terms of the number of days' wages it would cost the least paid public servant were analysed.

Results: The availability of inhaled short acting beta agonists (SABA), oral leukotriene receptor antagonists (LTRA), inhaled LABA-ICS combinations and inhaled corticosteroids (ICS) in all the study sites was 75\%, 60.8\%, 46.9\% and 45.4\% respectively. None of the study sites had inhaled long acting anti muscarinic agents (LAMA) and inhaled long acting beta agonist (LABA)-LAMA combinations. Spirometry and peak flow-metry as diagnostic tests were available in $24.4 \%$ and $6.7 \%$ of the study sites respectively. Affordability ranged from 2.2 days' wages for inhaled salbutamol to 17.1 days' wages for formoterol/budesonide inhalers and 27.8 days' wages for spirometry.

Conclusion: Medicines and diagnostic tests essential in asthma and COPD care are not widely available in Uganda and remain largely unaffordable. Strategies to improve access to affordable asthma and COPD medicines and diagnostic tests should be implemented in Uganda.
\end{abstract}

Keywords: Access, Medicines, Diagnostic tests, Asthma, COPD, Sub Saharan Africa, Uganda

\section{Background}

Globally, chronic respiratory diseases pose a major public health threat. Notably, the burden of asthma and chronic obstructive pulmonary disease (COPD) is steadily increasing in both developed and developing countries. According to recent World Health Organisation (WHO) estimates, about 235 million people have asthma

\footnotetext{
*Correspondence: kibirigedavis@gmail.com

'Department of Medicine, Uganda Martyrs Hospital Lubaga, P.O. BOX 7146, Kampala, Uganda

${ }^{2}$ Medical unit, GlaxoSmithKline Pharmaceutical Kenya Limited, Kampala, Uganda

Full list of author information is available at the end of the article
}

and 65 million people have moderate to severe COPD. High rates of mortality due to both conditions have been documented in low-and middle income countries (LMIC). In 2012, > three million people died of COPD, which accounted for about $6 \%$ of the all the deaths globally. An estimated $90 \%$ of these deaths occurred in LMIC [1].

In Uganda, a similar growing trend of mortality related to asthma and COPD has been described. A descriptive retrospective study conducted at an urban national referral hospital reported the burden of asthma and COPD of $70.6 \%$ and $21.6 \%$ respectively in 558 patients admitted to 
the hospital's adult pulmonology unit between December 2010 and August 2011. In hospital mortality among the patients admitted with asthma and COPD was $8.3 \%$ and 9.3\% respectively [2]. Another population based prospective cross sectional study performed in rural Masindi, a district in Western Uganda in 2012 reported the burden of COPD of $16.2 \%$ especially among participants of both gender aged 30-39 years [3]. This highlights that the COPD in Uganda primarily occurs among the young and this could probably be due to effects of environmental factors like increased use of biomass fuel for cooking and early infections like tuberculosis and recurrent childhood pneumonia. The first and recently concluded nationwide population survey to determine the burden and predictors of asthma in Uganda, the Uganda National Asthma Survey (UNAS) has documented a prevalence of $9.8 \%$ with a higher prevalence of asthma reported in urban areas compared to rural areas (Kirenga B et al. Unpublished data, 2016).

Despite the increasing burden of asthma and COPD and related high mortality rates in LMIC, suboptimal care of patients with asthma and COPD is still very common in LMIC. The challenges of low availability of affordable medicines and diagnostic tests for asthma and COPD, poor health system structures coupled with low knowledge levels of asthma and COPD management among healthcare workers and patients contribute to the suboptimal care in LMIC [4-8].

The WHO strategy on secondary and tertiary prevention section of chronic respiratory diseases emphasises the need to strengthen health care by identifying costeffective interventions, upgrading standards and accessibility of care at different levels of the health care system and improving access to affordable medicines [9]. Improving access to affordable medicine is one of the key components of the millennium development goals (MDG) referred to as the MDG target 8E [10].

The main objective of this study was to provide contemporary information about the availability, cost and affordability of selected essential medicines and diagnostic tests for asthma and COPD in Uganda, as recommended by the Global INitiative for Asthma (GINA) guidelines [11], Global initiative for chronic Obstructive Lung Disease (GOLD) guidelines [12], WHO guidelines of asthma and COPD management and are included in the WHO essential drug list for management of asthma and COPD [1, 13] and Uganda Clinical Guidelines (UCG).

This data will help guide a pragmatic approach to address the low access to affordable asthma and COPD medicines and diagnostic tests. It will also guide healthcare managers in Uganda on resource mobilisation and allocation for essential medicines and diagnostic tests for asthma and COPD. The data obtained will add to the existing literature on extent of availability, cost and affordability of essential asthma and COPD medicines and diagnostic tests in LMIC.

\section{Methods}

\section{Study settings and selection of study sites}

This was a cross sectional study that was conducted from 15th January 2017 to 28th February 2017 in 23 public hospitals, 22 private hospitals and 85 privately owned pharmacies that were randomly selected from the 4 regions of Uganda. The central, eastern, western and northern regions accounted for $55.4 \%, 20 \%, 16.2 \%$ and $8.4 \%$ of the selected study sites respectively (Fig. 1 shows geographical location of the study sites).

All the selected hospitals were tertiary hospitals, served a significantly large local population in each geographical location and had a daily or weekly functioning outpatient general medical or respiratory clinic. None was a specialist hospital. The pharmacies selected were those in close proximity to a tertiary hospital or a health centre IV (secondary hospital) serving a large local population and are licensed by the regulatory body (National Drug Authority) to sell all classes of medicines.

A total of 2 public and 2 private hospitals were excluded because they lacked a regular outpatient medical specialist clinic. Drug shops were not included because they are not licensed to sell essential medicines for NCD. A total of 30 pharmacies were excluded because the staff declined to provide the desired information on availability and cost of the study drugs.

According to the registry of ministry of Health, Republic of Uganda, there are 2 national referral hospitals, 14 regional referral hospitals and 139 general hospitals. About 41.9\% are government owned, $40.7 \%$ are private not for profit (PNFP) and $17.4 \%$ are private for profit [14].

Medical care in the public hospitals is paid for the government of Uganda. A national procurement institution called the National Medical Stores (NMS) is constitutionally mandated to procure and distribute all drugs and diagnostic tests for all government hospitals. Despite this, stock out of drugs and diagnostic tests is a common finding in most public hospitals. Patients seek medical care from private hospitals and pharmacies as a second option in cases of unavailability of drugs and diagnostic tests. These procure their drugs and diagnostic tests from private companies. According to 2016/17 Uganda National Household Survey (UNHS) conducted by the Uganda Bureau of Statistics (UBOS) to collect information on socio-economic characteristics at both household and community levels with an aim of monitoring development performance of key sectors, about $48 \%$ and $34 \%$ of surveyed participants sought medical care from private clinics/hospitals and public hospitals respectively. 


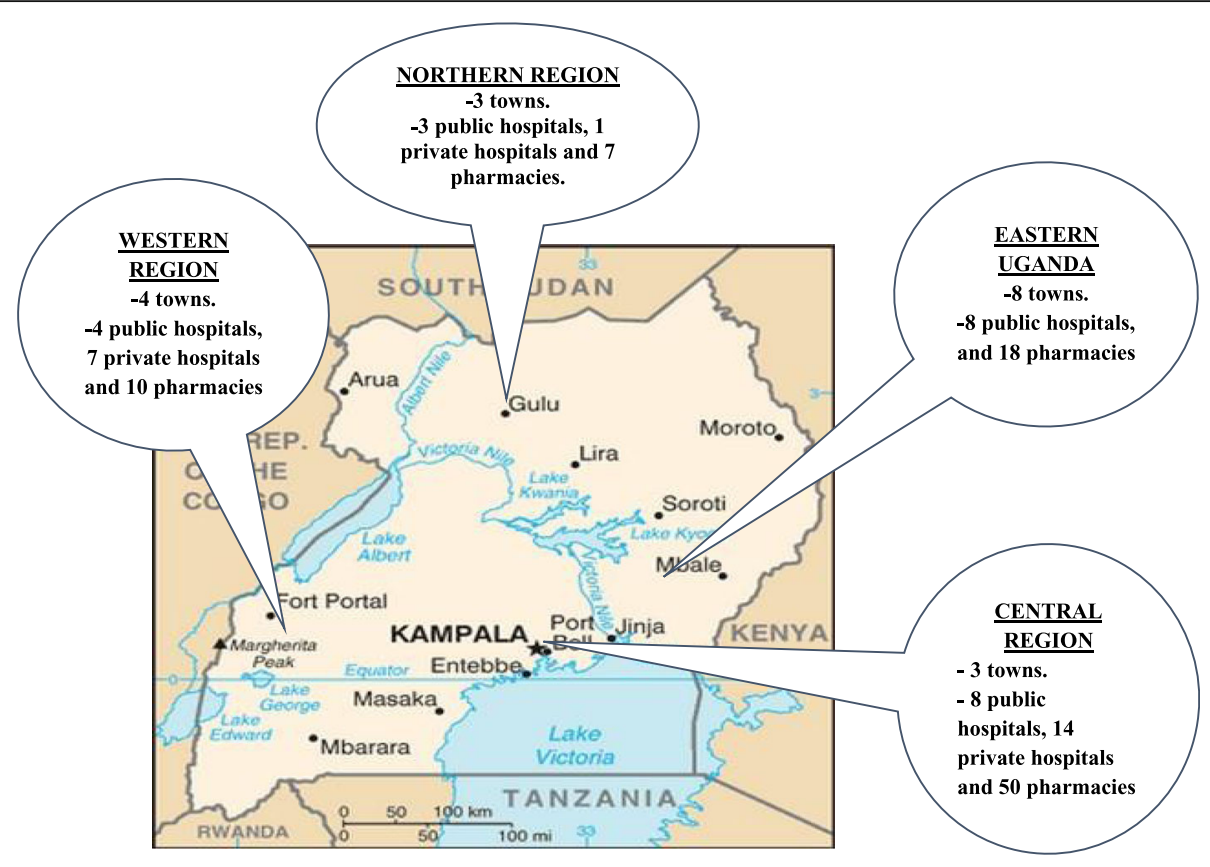

Fig. 1 Geographical location of the selected study sites. Map of Uganda obtained from Wikimedia Commons. https://commons.wikimedia.org/wiki/Maps_of_Uganda\#/media/File:Ug-map.png

Patients also sought medical care from private pharmacies and village health workers [15].

About 599 privately owned retail pharmacies and 90 private hospital pharmacies that sell human pharmaceutical drugs are registered by the National Drug Authority. About more than $70 \%$ of these are in the central region [16].

This study was conducted as a sub-section of the large study called the Access to Cardiovascular diseases, Chronic Obstructive pulmonary disease, Diabetes mellitus and Asthma Drugs and diagnostics (ACCODAD) study that assessed the availability and affordability of essential medicines and diagnostic tests of non-communicable diseases (NCD) in Uganda. The first published study from the ACCODAD study assessed access to key drugs and diagnostic tests in the management of diabetes and cardiovascular diseases [17].

\section{Sample size estimation}

Basing on one of the primary objectives of the ACCODAD study which was to determine the extent of availability of the medicines and diagnostic tests of interest, the overall availability of Pulmicort $^{\circ}$ (budesonide) in a study by Babar $\mathrm{Z}$ et al. in 52 surveyed LMICs of $8.3 \%$ was used as the prevalence $(P)$ [7]. Using the formula: $n=\mathrm{Z} 2 \mathrm{P}(1-\mathrm{P}) / \mathrm{d} 2$ where $\mathrm{Z}$ (normal value corresponding to the $95 \%$ confidence interval $)=1.96, P$ $=0.083$ and $\mathrm{d}=0.05$ (desired precision of estimation), a sample size of 117 healthcare units (public and private hospitals and private pharmacies) was obtained. We increased the sample size of the surveyed health units to 130 to generate adequate information. We aimed at surveying a minimum of $10 \%$ of the registered public and private hospitals and private pharmacies in Uganda.

\section{Data collection}

Data was collected using a pre tested questionnaire based on the WHO and Health Action International (HAI) standardised methods of assessing medicine availability, prices and affordability in LMIC [18] from 15th January 2017 to 28th February 2017. The study data collection team underwent a brief training before commencement of the study to improve quality and standardisation of data.

The diagnostic tests of interest of asthma and COPD in this study were spirometry and peak flow-metry. The medicines of interest were: inhaled short acting beta agonists (SABA) like salbutamol meter dose inhaler (MDI) $100 \mu \mathrm{g}$, inhaled short acting anti muscarinic agents (SAMA) like ipratropium bromide 20 and $40 \mu \mathrm{g}$ MDI, inhaled long acting anti muscarinic agents (LAMA) like tiotropium $18 \mu \mathrm{g}$ dry powder inhalers (DPI), inhaled SABA and SAMA combinations like salbutamol/ipratropium 100/20 $\mu \mathrm{g}$ soft mist inhaler (SMI), inhaled LABA and LAMA combinations like olodaterol/tiotropium 5/ $5 \mu \mathrm{g}$ SMI, inhaled LABA-inhaled corticosteroid (ICS) combinations like formoterol-budesonide 4.5/160 $\mu \mathrm{g}$ MDI and salmeterol-fluticasone propionate 25/125 $\mu \mathrm{g}$ MDI, ICS like budesonide $200 \mu \mathrm{g}$ DPI and fluticasone propionate $250 \mu \mathrm{g}$ DPI, oral methylxanthines like slow 
release theophylline $100 \mathrm{mg}$ and oral leukotriene receptor antagonists (LTRA) like tablets montelukast $10 \mathrm{mg}$ and $20 \mathrm{mg}$. Adult and paediatric spacer devices were also included due to their integral role in asthma and COPD management especially in young children and elderly patients.

Information about the availability of each stated medicine category and monthly cost of the available lowest priced generic medicine was obtained. The cost of the medicines obtained was the retail prices charged directly to the patients at the respective pharmacies of the private hospitals and private pharmacies. Information about the availability and cost of the diagnostic tests of interest was only obtained from the hospitals.

The cost of the medicines in the public hospitals was not obtained since medical care is offered free of charge. All the costs of the medicines and the diagnostic tests were obtained in Uganda shillings (UgX) and converted to US dollars (USD) according to the existing exchange rate at the time of data collection $(1 \mathrm{USD}=3600 \mathrm{UgX})$.

\section{Data analysis}

Availability of the medicine categories were assessed using simple descriptive statistics by calculating the proportions of hospitals and private pharmacies in which any type and dose of the medicine and diagnostic test was present on the day of data collection at the study site. The study definition of low, moderate and high availability of the selected medicines and diagnostic tests at any study site was $<50 \%, 50-79 \%$ and $\geq 80 \%$ respectively. The availability of the selected diagnostic tests and medicines was compared between the study sites and study regions using chi-square test to determine significant differences. A $p$ value of $<0.05$ was considered as statistically significant.

The unit prices of the medicines in USD were converted to a median price ratio (MPR) by dividing the median local price by an international reference price (IRP). The IRP is obtained from the Management Sciences for Health International Drug Price Indicator Guide which reports median prices of high quality multisource medicines offered to LMICs countries by different suppliers. The MPR is used to express how much greater or less the median local medicine price is than the IRP. An MPR of 3 would mean that the local medicine price is three times greater than the IRP. The study definition of reasonable pricing was when the MPR of a patient's medicine was $<1.5$ [19]. The cost of the available lowest priced generic medicine was compared to the cost of the available originator brand medicine.

Affordability was estimated using the median monthly medicine prices and the average salary of the lowest paid government worker in USD and calculating the number of days' wages required to purchase a one-month course of treatment or to pay for a specific diagnostic test. Medicines and diagnostic tests that cost $\leq 3$ days' wages were considered affordable.

The lowest paid skilled government worker at the time of the study (scale U8 lower-non formal education teachers) earns a gross salary of 198,793 UgX equivalent to 55.2 USD. After tax deductions, this translates to a net salary of $139,155 \mathrm{UgX}$ equivalent to $38.7 \mathrm{USD}$ per month or $4638.5 \mathrm{UgX}$ (1.3 USD daily) [20].

\section{Results}

Availability of the medicines and diagnostic tests

The availability of the selected medicines ranged from $0 \%$ for inhaled LAMA and inhaled LAMA-LABA combinations to $75 \%$ for SABA. Inhaled SABA-SAMA combinations, inhaled SAMA, oral methylxanthines, ICS, LABA-ICS and oral LTRA were available in $10.8 \%$, $12.3 \%, 16.9 \%, 45.4 \%, 46.9 \%$ and $60.8 \%$ respectively in all study sites. Adult and paediatric spacers were available in only $18.5 \%$ and $19.2 \%$ of study sites respectively. Spirometry and peak flow-metry were available in only $24.4 \%$ and $6.7 \%$ of the study sites respectively (summarised in Table 1).

\section{Comparison of the availability of selected medicines in the study sites and regions}

There was a stark difference in availability of medicines in the study sites and regions. Low availability of medicines was mostly documented in the public hospitals compared to private hospitals and pharmacies. The only available medicines in the public hospitals were: inhaled SABA in $26.1 \%$ compared to $77.3 \%$ and $88.2 \%$ in private hospitals and pharmacies respectively $(p<0.001)$, ICS in $4.4 \%$ compared to $50 \%$ and $55.3 \%$ in private hospitals and pharmacies respectively $(\mathrm{p}<0.001)$ and oral methylxanthines in $4.4 \%$ compared to $18.2 \%$ and $20 \%$ in private hospitals and pharmacies respectively $(p=0.203)$. Comparing private hospitals and private pharmacies, the selected medicines were more available in the latter. Of the 3 study sites categories, inhaled LABA, SAMA and adult spacers were only available in private pharmacies (15.3\%, 18.8\% and $28.2 \%$ respectively) (summarised in Table 1). All the medicines of interest except inhaled LABA were more available in the central region (summarised in Table 2).

\section{Comparison of the availability of selected diagnostic tests in private and public hospitals}

There was no documented statistically significant difference in the availability of spirometry and peak flowmetry in private and public hospitals. Spirometry was available in $13.6 \%$ and $34.8 \%$ of private and public hospitals respectively $(p=0.099)$ while peak flow-metry were 
Table 1 Availability of the asthma-COPD drugs and diagnostic tests in private and public hospitals and private pharmacies $(n=130)$

\begin{tabular}{|c|c|c|c|c|c|}
\hline \multirow[b]{2}{*}{ A: Selected medicines ( $N=10$ classes and 2 types of spacers) } & \multirow[b]{2}{*}{$\begin{array}{l}\text { Availability }(\%) \text { in all } \\
\text { study sites }(N=130)\end{array}$} & \multicolumn{4}{|l|}{ Availability (\%) } \\
\hline & & $\begin{array}{l}\text { Public hospitals } \\
(N=23)\end{array}$ & $\begin{array}{l}\text { Private hospitals } \\
(N=22)\end{array}$ & $\begin{array}{l}\text { Private pharmacies } \\
(N=85)\end{array}$ & $P$ value \\
\hline Inhaled LAMA monotherapies & 0.0 & 0.0 & 0.0 & 0.0 & NA \\
\hline Inhaled LABA and LAMA combinations & 0.0 & 0.0 & 0.0 & 0.0 & NA \\
\hline Inhaled LABA monotherapies & 10.0 & 0.0 & 0.0 & 15.3 & 0.022 \\
\hline Inhaled SABA and SAMA combinations. & 10.8 & 0.0 & 4.6 & 15.3 & 0.065 \\
\hline Inhaled SAMA monotherapy & 12.3 & 0.0 & 0.0 & 18.8 & 0.008 \\
\hline Oral methylxanthines & 16.9 & 4.0 & 18.2 & 20.0 & 0.203 \\
\hline Adult spacer devices & 18.5 & 0.0 & 0.0 & 28.2 & $<0.001$ \\
\hline Paediatric spacer devices & 19.2 & 0.0 & 4.6 & 28.2 & 0.002 \\
\hline ICS monotherapies & 45.4 & 4.0 & 50.0 & 55.3 & $<0.001$ \\
\hline Inhaled LABA- ICS combinations & 46.9 & 0.0 & 40.9 & 61.2 & $<0.001$ \\
\hline Oral LTRA & 60.8 & 0.0 & 59.1 & 76.7 & $<0.001$ \\
\hline Inhaled SABA monotherapy & 75.0 & 26.1 & 77.3 & 88.2 & $<0.001$ \\
\hline \multicolumn{6}{|l|}{ B: Diagnostic/monitoring tests } \\
\hline Peak flow-metry & 6.7 & 8.7 & 4.6 & NA & 0.577 \\
\hline Spirometry & 24.4 & 34.8 & 13.6 & NA & 0.099 \\
\hline
\end{tabular}

LAMA-Long acting anti muscarinic agents, LABA-Long acting beta agonists, SABA-Short acting beta agonists, SAMA-Short acting anti muscarinic agents, ICSInhaled corticosteroids, LTRA-Leukotriene receptor antagonists

available in $4.6 \%$ and $8.7 \%$ of private and public hospitals respectively ( $p=0.577$ ) (summarised in Table 1 ).

\section{Comparison of the median cost of the lowest priced generic and originator brand in the private hospitals and pharmacies \\ With the exception of Combivent ${ }^{\oplus}$ (salbutamol/ipratro-} pium $100 / 20 \mu \mathrm{g}$ soft mist inhaler), the median prices of all originator brands were higher than the obtained median prices of the generic brands. Marked differences in median prices were noted with formoterol/budesonide 4.5/160 $\mu \mathrm{g}$ LABA-ICS combination, ICS budesonide $200 \mu \mathrm{g}$ and all doses of the ICS fluticasone propionate $250 \mu \mathrm{g}, 125 \mu \mathrm{g}$ and $50 \mu \mathrm{g}$. The cost of generic and originator montelukast $20 \mathrm{mg}$ brands were similar (summarised in Table 3).

Table 2 Availability of the asthma-COPD drugs in the 4 study regions

\begin{tabular}{|c|c|c|c|c|c|}
\hline \multirow[b]{2}{*}{ Selected medicines ( $N=10$ classes and 2 types of spacers) } & \multicolumn{5}{|l|}{ Availability (\%) } \\
\hline & Central region & Eastern region & Western region & Northern region & $P$ value \\
\hline Inhaled LABA and LAAC combinations & 0.0 & 0.0 & 0.0 & 0.0 & NA \\
\hline Inhaled LAAC monotherapies & 0.0 & 0.0 & 0.0 & 0.0 & NA \\
\hline Inhaled LABA monotherapies & 9.7 & 4.2 & 4.6 & 33.3 & 0.031 \\
\hline Inhaled SABA and SAAC combinations & 19.4 & 0.0 & 0.0 & 0.0 & 0.005 \\
\hline Inhaled SAAC monotherapy & 22.2 & 0.0 & 0.0 & 0.0 & 0.002 \\
\hline Oral methylxanthines & 22.2 & 16.7 & 4.6 & 8.3 & 0.215 \\
\hline Adult spacer devices & 25.0 & 8.3 & 13.6 & 8.3 & 0.184 \\
\hline Paediatric spacer devices & 30.6 & 4.2 & 4.6 & 8.3 & 0.004 \\
\hline Inhaled LABA-ICS combinations & 61.1 & 25.0 & 31.8 & 33.3 & 0.004 \\
\hline ICS monotherapies & 61.1 & 37.5 & 9.1 & 33.3 & $<0.001$ \\
\hline Oral LTRA & 75.0 & 37.5 & 50.0 & 41.7 & 0.002 \\
\hline Inhaled SABA monotherapy & 80.6 & 70.8 & 68.2 & 66.7 & 0.490 \\
\hline
\end{tabular}

LAMA-Long acting anti muscarinic agents, LABA-Long acting beta agonists, SABA-Short acting beta agonists, SAMA-Short acting anti muscarinic agents, ICSInhaled corticosteroids, LTRA-Leukotriene receptor antagonists 
Table 3 Comparison of the median prices of the inhaled and oral generic and originator asthma and COPD medicine brands

\begin{tabular}{|c|c|c|c|c|c|}
\hline Generic brands & $\begin{array}{l}\text { Median (IQR) price } \\
\text { in UgX }\end{array}$ & $\begin{array}{l}\text { Median (IQR) price } \\
\text { in USD }\end{array}$ & Originator brands & $\begin{array}{l}\text { Median (IQR) price } \\
\text { in UgX }\end{array}$ & $\begin{array}{l}\text { Median (IQR) price } \\
\text { in USD }\end{array}$ \\
\hline Salbutamol $100 \mu \mathrm{g}$ & $10,000(9000-13,000)$ & $2.8(2.5-3.6)$ & Ventolin $100 \mu \mathrm{g}$ & $12,000(10000-15,000)$ & $3.3(2.8-4.2)$ \\
\hline Ipratropium bromide $20 \mu \mathrm{g}$ & $60,000(48500-65,000)$ & $16.7(13.5-18.1)$ & Atrovent $20 \mu \mathrm{g}$ & $62,500(60000-65,000)$ & $17.4(16.7-18.1)$ \\
\hline Ipratropium $40 \mu \mathrm{g}$ & $64,000(56750-65,000)$ & $17.8(15.8-18.1)$ & Atrovent $40 \mu \mathrm{g}$ & $65,000(65000-70,000)$ & $18.1(18.1-19.4)$ \\
\hline Salbutamol/ipratropium 100/20 mg & $50,000(35000-65,000)$ & $13.9(9.7-18.1)$ & Combivent $100 / 20 \mu \mathrm{g}$ & $40,000(30000-50,000)$ & $11.1(8.3-13.9)$ \\
\hline Formoterol-budesonide 4.5/160 $\mu \mathrm{g}$ & $80,000(45000-85,000)$ & $22.2(12.5-23.6)$ & Symbicort 4.5/160 $\mu \mathrm{g}$ & $100,000(85000-120,000)$ & $27.8(23.6-33.3)$ \\
\hline $\begin{array}{l}\text { Salmeterol-fluticasone propionate } \\
25 / 125 \mu \mathrm{g}\end{array}$ & $48,000(35000-50,000)$ & $13.3(9.7-13.9)$ & Seretide $25 / 125 \mu \mathrm{g}$ & $50,000(48000-60,000)$ & $13.9(13.3-16.7)$ \\
\hline Budesonide $200 \mu \mathrm{g}$ & $37,500(33000-42,000)$ & $10.4(9.2-11.7)$ & Pulmicort $200 \mu \mathrm{g}$ & $100,000(75000-130,000)$ & $27.8(20.8-36.1)$ \\
\hline Fluticasone propionate $250 \mu \mathrm{g}$ & $25,000(25000-26,000)$ & $6.9(6.9-7.2)$ & Flixotide $250 \mu \mathrm{g}$ & $87,500(80000-95,000)$ & $24.3(22.2-26.4)$ \\
\hline Fluticasone propionate $125 \mu \mathrm{g}$ & $27,000(25000-40,000)$ & $7.5(6.9-11.1)$ & Flixotide $125 \mu \mathrm{g}$ & $87,500(87500-87,500)$ & $24.3(24.3-24.3)$ \\
\hline Fluticasone propionate $50 \mu \mathrm{g}$ & $27,500(25000-30,000)$ & $7.6(6.9-8.3)$ & Flixotide $50 \mu \mathrm{g}$ ) & $78,500(78500-78,500)$ & $21.8(21.8-21.8)$ \\
\hline Tablets montelukast $10 \mathrm{mg}$ & $1000(800-1200)$ & $0.3(0.2-0.3)$ & Singular $10 \mathrm{mg}$ & $1100(900-1400)$ & $0.3(0.3-0.4)$ \\
\hline Tablets montelukast 20 mg & $1200(1000-1500)$ & $0.3(0.3-0.4)$ & Singular $20 \mathrm{mg}$ & $1200(1100-1500)$ & $0.3(0.3-0.4)$ \\
\hline
\end{tabular}

IQR-Inter-quartile range, UgX-Uganda shillings, USD-US dollars

\section{Pricing and affordability of the medicines and diagnostic tests \\ Selected medicines}

The IPR were only available for salbutamol $100 \mu \mathrm{g}$ inhalers, ipratropium $20 \mu \mathrm{g}$ inhalers, beclometasone $100 \mu \mathrm{g}$ inhalers, budesonide $200 \mu \mathrm{g}$ inhalers and fluticasone propionate $125 \mu \mathrm{g}$. According to the calculated MPR, these drugs were all highly priced with the local retail prices being $>100$ times the IRP.

Affordability of the drugs ranged from 2 days' wages for salbutamol $100 \mu \mathrm{g}$ metered dose inhalers to 17 days' wages for formoterol-budesonide 4.5/160 $\mu \mathrm{g}$ LABA-ICS combination. According to the study definition of affordability, salbutamol $100 \mu \mathrm{g}$ MDI was the only affordable asthma and COPD medicine. With the exception of fluticasone propionate $125 \mu \mathrm{g}$ inhalers (cost 10 days' wages) and budesonide $200 \mu \mathrm{g}$ inhalers (cost 8 days' wages), the rest of controller or maintenance medicines cost $\leq 7$ days' wages.

Inhaled ipratropium either as monotherapy or in combination with salbutamol as reliever medicines were largely unaffordable, with costs of up to 8 to 14 days' wages. Both adult and paediatric spacers were also largely unaffordable (costs of 13 and 8 days' wages respectively).

(Pricing and affordability of medicines is summarised in Table 4).

\section{Diagnostic tests}

The cost of performing spirometry was obtained from only 2 surveyed hospitals because the other hospitals offer it free of charge. The median cost of performing spirometry was 130,000 UgX (36.1 USD) which translates to 27.8 days' wages.

\section{Discussion}

Availability of the medicines and diagnostic tests

This study aimed at providing contemporary information about the availability, cost and affordability of medicines and diagnostic tests essential in asthma and COPD management in Uganda. To our knowledge, this is the largest study to investigate the availability, cost and affordability of these essential medicines and diagnostic tests in Uganda.

Generally, all the selected asthma and COPD medicines and diagnostic tests were either of moderate or low availability. The lowest levels of availability were in public hospitals. The only available medicines in the public hospitals were inhaled SABA in $26.1 \%$, ICS and oral methylxanthines (both in 4.4\%). This low availability of essential medicines of asthma and COPD in our study has also been widely reported in the majority of studies investigating access to chronic diseases medicines in LMIC [7, 21-23] and in the annual medicine price monitor studies in Uganda [24, 25].

In the study by Babar $\mathrm{Z}$ et al. performed in 52 LMIC (Uganda inclusive) to investigate the availability, pricing and affordability of 3 essential asthma medicines (inhaled salbutamol, beclometasone and budesonide); generic beclometasone and budesonide were available in only $19 \%$ and $16 \%$ of the surveyed public hospitals respectively and in $46 \%$ and $58 \%$ in the private sector respectively. The 2 ICS of interest were unavailable in 14 of the surveyed 52 LMIC. Generic salbutamol inhalers were available in $56 \%$ and $82 \%$ of the public hospitals and private pharmacies [7]. Similar findings of low availability of asthma medicines was also reported by another cross sectional study by Cameron A et al. performed in 36 LMIC (10 sub Saharan African countries including 
Table 4 Median (IQR) prices and affordability of the lowest priced generic inhaled asthma-COPD drugs in both private hospitals and pharmacies

\begin{tabular}{|c|c|c|c|c|c|c|}
\hline Drug & Median (IQR) price in Ug Shs & $\begin{array}{l}\text { Median local } \\
\text { price in USD }\end{array}$ & IRP in USD & MPR & $\begin{array}{l}\text { Monthly } \\
\text { cost in USD }\end{array}$ & Days' wages \\
\hline Salbutamol $100 \mu \mathrm{g}$ & $10,000(9000-13,000)$ & 2.8 & 0.0114 & 243 & 2.8 & 2.2 \\
\hline Formoterol $12 \mu \mathrm{g}$. & $38,500(30000-44,000)$ & 10.7 & - & - & 10.7 & 8.2 \\
\hline Salmeterol $25 \mu \mathrm{g}$ & $30,000(25500-33,750)$ & 8.3 & - & - & 8.3 & 6.4 \\
\hline Ipratropium bromide $20 \mu \mathrm{g}$ & $60,000(48500-65,000)$ & 10.7 & 0.0220 & 486 & 10.7 & 8.2 \\
\hline Ipratropium $40 \mu \mathrm{g}$ & $64,000(56750-65,000)$ & 17.8 & - & - & 17.8 & 13.7 \\
\hline Salbutamol/ipratropium 100/20 $\mu \mathrm{g}$ & $50,000(35000-65,000)$ & 13.9 & - & - & 13.9 & 10.7 \\
\hline Formoterol-beclomethasone $6 / 100 \mu \mathrm{g}$ & $30,000(15000-40,000)$ & 8.3 & - & - & 8.3 & 6.4 \\
\hline Formoterol-budesonide $4.5 / 160 \mu \mathrm{g}$ & $80,000(45000-85,000)$ & 22.2 & - & - & 22.2 & 17.1 \\
\hline Salmeterol-fluticasone propionate $25 / 125 \mu \mathrm{g}$ & $48,000(35000-50,000)$ & 13.3 & - & - & 13.3 & 10.2 \\
\hline Beclomethasone dipropionate 100 mg & $25,000(20000-30,000)$ & 6.9 & 0.0444 & 155 & 6.9 & 5.3 \\
\hline Budesonide $200 \mu \mathrm{g}$ & $37,500(33000-42,000)$ & 10.4 & 0.0305 & 340 & 10.4 & 8 \\
\hline Fluticasone propionate $250 \mu \mathrm{g}$ & $25,000(25000-26,000)$ & 6.9 & - & - & 6.9 & 5.3 \\
\hline Fluticasone propionate $125 \mu \mathrm{g}$ & $27,000(25000-40,000)$ & 7.5 & 0.0630 & 119 & 7.5 & 5.8 \\
\hline Fluticasone propionate $50 \mu \mathrm{g}$ & $27,500(25000-30,000)$ & 7.6 & - & - & 7.6 & 5.9 \\
\hline Slow release theophylline tablets $100 \mathrm{mg}$ & $1000(1000-1900)$ & 0.3 & - & - & 9 & 6.9 \\
\hline Tablets montelukast $10 \mathrm{mg}$ & $1000(800-1200)$ & 0.3 & - & - & 9 & 6.9 \\
\hline Tablets montelukast $20 \mathrm{mg}$ & $1200(1000-1500)$ & 0.3 & - & - & 9 & 6.9 \\
\hline Adult spacers & $60,000(51000-65,000)$ & 16.7 & - & - & 16.7 & 12.9 \\
\hline Paediatric spacers & $35,000(28500-45,000)$ & 9.7 & - & - & 9.7 & 7.5 \\
\hline
\end{tabular}

IQR-Inter-quartile range, UgX-Uganda shillings, USD-US dollars, IRP-International reference price, MPR-Median price ratio

Uganda). This study sought to assess the availability and pricing of 30 core medicines for acute and chronic diseases. The only surveyed asthma drug (inhaled salbutamol $100 \mu \mathrm{g}$ MDI) was on average available in $14 \%(0-55.9 \%)$ and $47 \%(0-95 \%)$ of the public hospitals and private pharmacies in the 8 participating African countries [21].

According to the medicine price monitoring study conducted in Uganda in 2014, the availability of the only assessed asthma medicine (salbutamol $100 \mu \mathrm{g}$ inhaler) was $13 \%, 54 \%$ and $56 \%$ in the surveyed public, private and mission or PNFP health facilities [22]. The 2015 medicine price monitoring study noted that salbutamol inhaler was available in $<25 \%$ of the public facilities [23].

The dismal availability of asthma and COPD medicines in Uganda especially in the public hospitals could be due to the few asthma and COPD medicines included in our essential drug list. Among the medicines of interest for this study, the asthma medicines section of the 2012 Uganda essential drug list included only aminophylline tablets, beclometasone and salbutamol inhalers [26]. These are also the only drugs recommended for management of asthma in the 2016 Uganda clinical guidelines (UCG). There is no recommendation for inhaled LABA-ICS combinations, inhaled LAMA, inhaled SAMA and oral LTRA in the management of asthma.
Despite the 2016 UCG recommendation to use ipratropium inhalers and inhaled LABA in combination with ICS in the management of COPD, both drugs were absent in all surveyed public and private hospitals. Ipratropium, a key SAMA was only available in private pharmacies (18.8\%).

Other essential medicines in COPD management like inhaled LAMA (either as monotherapy/in combination with LABA) were not available in any study site. This could also probably be due to their absence in the Ugandan clinical guidelines and essential drug lists. The overall low and moderate availability of the key asthma and COPD medicines in the study could also be explained by the evident knowledge gaps and inapt prescription practices among healthcare practitioners in Uganda with regard to asthma and COPD management. A retrospective study evaluating asthma medication prescription practices of healthcare practitioners at the chest clinic and accident and emergency department of a national referral hospital in Uganda noted a high frequency of prescription of oral salbutamol (>50\%), oral prednisolone (64.2\%) and oral aminophylline (16\%) in the chest clinic. Inhaled beta agonists and ICS were only used in $38 \%$ and $24 \%$ of the patients [5].

Low availability of spacers which are key in facilitating optimal delivery of inhaled medicines in young children 
and elderly patients with poor inspiratory effort $(<20 \%$ in all study sites) and the diagnostic tests (spirometry and peak flow-metry $<25 \%$ and $<10 \%$ respectively) was well documented in both the public and private sector. Availability of spacers and diagnostic tests has not been widely studied in most studies assessing access to asthma and COPD medicines and diagnostics in LMIC.

\section{Affordability of the medicines and diagnostic tests}

With the exception of salbutamol inhalers, the rest of the asthma and COPD medicines were largely unaffordable when accessed from the private sector. From the list of medicines of interest, the cheapest inhaled LABA (salmeterol $25 \mu \mathrm{g}$ MDI), inhaled SAMA (ipratropium $20 \mu \mathrm{g}$ ), inhaled SABA-SAMA combination (salbutamol/ipratropium 100/20 $\mu \mathrm{g}$ ), ICS (beclometasone $100 \mu \mathrm{g} /$ fluticasone propionate $250 \mu \mathrm{g}$ ) and inhaled LABA-ICS combination (formoterol-beclometasone $6 / 100 \mu \mathrm{g}$ ) would cost 6 days' wages, 8 days' wages, 11 days' wages, 5 days' wages and 6 days' wages of the least paid government employee respectively. All recommended oral controller therapies (methylxanthines and LTRA) would cost about 7 days' wages.

The cheapest standard generic asthma and COPD treatment regimen of an inhaled SABA (used on an as needed basis) and ICS-LABA combination would collectively cost 11.1 USD which translates to 8.6 days' wages of the least paid government employee. A combination regimen of the cheapest generic SABA inhaler (salbutamol inhaler $100 \mu \mathrm{g}$ ) and ICS (beclometasone inhaler $100 \mu \mathrm{g}$ ) would cost 9.7 USD or 7.5 days' wages.

A wide variation in affordability of asthma and COPD medicines has been reported in the majority of similar studies across different countries. In one study investigating the availability and affordability of essential medicines in 6 LMIC documented the cost of standard asthma combination therapy of the lowest priced generic salbutamol and beclometasone inhalers were 1.3 days' wages in Bangladesh, 9.2 days' wages in Malawi, 5.4 days' wages in Nepal, 2.5 days' wages in Pakistan and 2.3 days' wages in Sri Lanka [22]. The cost of similar combination therapy in another study performed in India was 2 days' wages [27]. Salbutamol inhaler remains affordable in Uganda. The 2014 and 2015 medicine price monitor studies performed in Uganda reported the cost of only salbutamol $100 \mu \mathrm{g}$ inhaler of 1.4 and 1.6 days' wages respectively [24, 25] compared to 2.2 days wages' in our study. Other asthma and COPD drugs were not studied.

The majority of asthma and COPD medicines being unaffordable in the private sector in this study could probably be explained by the lack of a national policy or legislation to regulate retail prices of medicines especially for chronic diseases. Uganda also lacks a vibrant local pharmaceutical industry sector that would manufacture cheap quality generic asthma and COPD medicines for the public and private sector.

There is paucity of studies investigating the cost and affordability of performing spirometry in LMIC. The cost equivalent to 27.8 days' wages reported by our study findings is unaffordable to the majority of Ugandan patients with asthma and COPD. This could be due to the limited hospitals and expertise capable of rendering this specialist service.

\section{Conclusions}

This study demonstrated that the majority of asthma and COPD medicines and diagnostic tests were largely unavailable especially in the public hospitals and unaffordable in the private sector. In the public sector, inequity in access to medicines and diagnostic tests for asthma and COPD care can be addressed through increased awareness about optimal management of asthma and COPD among healthcare practitioners and patients, inclusion of other essential asthma and COPD medicines on the national essential drug list and clinical care guidelines, improving forecast accuracy, procurement efficiency and stock handling and boosting local production of cheap quality generic asthma and COPD medicines. At the private sector level, access to affordable medicines can be improved through implementation of national policies aimed at regulating retail prices of medicines especially for chronic care, improving forecast accuracy, procurement efficiency, stock handling and local production of cheap generic medicines. Due to the prohibitive costs of diagnosis and management of asthma and COPD in Uganda, national primary prevention strategies for chronic respiratory diseases should be widely implemented to reduce the disease burden.

\section{Study limitations}

The data was collected at one point in time which does not put into consideration the temporal variations in availability and prices of medicines over time in the different surveyed hospitals and private pharmacies hence, we cannot establish a causal relationship between the investigated outcome of interest and the risk factors. Misreporting (under-or over-reporting) of the data is highly possible due to selection, information or recall bias and the one point in time approach of data collection.

Assessment of drug stock records was not performed to ascertain availability of drugs. We were unable to obtain the national procurement or tender prices of the mandated government institution (NMS) to procure and supply medicines to all government hospitals. These would accurately reflect the prices of the few drugs procured for the public hospitals in comparison 
the private hospitals and pharmacies. Using the daily wage of the lowest paid unskilled government to calculate affordability of medicines and diagnostic tests has its limitations because a significant proportion of the Ugandan population earns less than 1.3 USD per day.

Despite these limitations, the standardised WHO/HAI methodology that was used has been widely validated. This is the largest study to comprehensively assess the availability and affordability of several locally and internationally guideline recommended inhaled and oral asthma and COPD medicines and diagnostic tests in Uganda.

\section{Abbreviations \\ ACCODAD: Access to cardiovascular diseases, chronic obstructive pulmonary diseases, diabetes and asthma drugs and diagnostics study; COPD: Chronic obstructive pulmonary disease; GINA: Global initiative for asthma; GOLD: Global initiative for chronic obstructive lung disease; HAl: Health Action International; ICS: Inhaled corticosteroids; IRP: International reference price; LABA: Long acting beta agonists; LAMA: Long acting anti muscarinic agents; LTRA: Leukotriene receptor antagonists; MPR: Median price ratio; NMS: National medical stores; SABA: Short acting beta agonists; SAMA: Short acting anti muscarinic agents; UgX: Uganda shillings; USD: United States dollars; WHO: World Health Organisation}

\section{Acknowledgments}

We would like to recognise and thank the entire study data collection team and the Uganda Diabetes Association for offering the small grant that supported this research project.

\section{Funding}

This study was supported by a small grant from Uganda Diabetes Association, a diabetes professional association for diabetic patients and healthcare practitioners.

\section{Availability of data and materials}

The data set in form of an excel file supporting the results of this article is available when requested.

\section{Authors' contributions \\ DK, LK, DA, RM, WK, WM, RN, WW and BK collectively contributed to the design of the study, data collection, drafting of the initial manuscript, appraisal and approval of the final submitted manuscript. DK and LK performed the statistical analysis All authors read and approved the final manuscript.}

\section{Ethics approval and consent to participate}

Ethical approval to conduct this study was granted by the ethics review board of St. Francis hospital, Nsambya Uganda as approved by the Uganda National Council of Science and Technology (UNCST).

\section{Consent for publication}

No individual person's data in any form (details, image and videos) was used in this manuscript.

\section{Competing interests}

DK works in the medical unit of GlaxoSmithKline (GSK) pharmaceutical Kenya Limited in Uganda. GSK did not participate in the study funding, design or analysis of the data. The views expressed in this manuscript are solely the author's (DK). The rest of the authors declare no competing interests.

\section{Publisher's Note}

Springer Nature remains neutral with regard to jurisdictional claims in published maps and institutional affiliations.

\section{Author details}

'Department of Medicine, Uganda Martyrs Hospital Lubaga, P.O. BOX 7146, Kampala, Uganda. ${ }^{2}$ Medical unit, GlaxoSmithKline Pharmaceutical Kenya Limited, Kampala, Uganda. ${ }^{3}$ Infectious Disease Research Collaboration (IDRC), Kampala, Uganda. ${ }^{4}$ Department of Medicine, Case hospital Kampala, Kampala, Uganda. ${ }^{5}$ Department of Medicine, St. Francis hospital Nsambya, Kampala, Uganda. ${ }^{6}$ Makerere Lung Institute, Makerere University College of Health Sciences, Kampala, Uganda. ${ }^{7}$ Department of Paediatrics and Child Health, Makerere University College of Health Sciences, Kampala, Uganda. ${ }^{8}$ Division of Pulmonology, Mulago National Referral and Teaching hospital, Kampala, Uganda.

Received: 24 April 2017 Accepted: 24 November 2017

Published online: 08 December 2017

References

1. WHO. Chronic respiratory diseases. 2016. http://www.who.int/respiratory/ en/. Accessed 11 Jan 2017

2. Kirenga B, Nakiyingi L, Worodria W, Okot-Nwang M. Chronic respiratory diseases in a tertiary healthcare facility in Uganda. African journal of. Respir Med. 2013;8(2):21-3.

3. van Gemert F, Kirenga B, Chavannes N, Kamya M, Luzige S, Musinguzi P, et al. Prevalence of chronic obstructive pulmonary disease and associated risk factors in Uganda (FRESH AIR Uganda): a prospective cross-sectional observational study. Lancet Glob Health. 2015;3:e44-51.

4. Serugendo A, Kirenga B, Hawkes M, Nakiyingi L, Worodria W, Okot-Nwang M. Evaluation of asthma control using global initiative for asthma criteria and the asthma control test in Uganda. Int J Tuberc Lung Dis. 2014;18(3):371-6.

5. Kirenga B, Okot-Nwang M. The proportion of asthma and patterns of asthma medications prescriptions among adult patients in the chest, accident and emergency units of a tertiary health care facility in Uganda. Afr Health Sci. 2012;12(1):48-53.

6. Obaseki D, Adeniyi B, Kolawole T, Onyedum C, Erhabor G. Gaps in capacity for respiratory Care in Developing Countries: Nigeria as a case study. Ann Am Thorac Soc. 2015;12(4):591-8.

7. Babar Z, Lessing C, Mace C, Bissell K. The availability, pricing and affordability of three essential asthma medicines in 52 low- and middleincome countries. PharmacoEconomics. 2013;31:1063-82.

8. Beran D, Zar H, Perrin C, Menezes A, Burney P. Burden of asthma and chronic obstructive pulmonary disease and access to essential medicines in low-income and middle-income countries: for the forum of international respiratory societies working group collaboration. Lancet Respir Med. 2015; 3:159-70.

9. WHO. WHO Strategy for prevention and control of chronic Respiratory Diseases. http://www.who.int/respiratory/publications/strategy/en/index5. html. Accessed 1 Dec 2017.

10. Millennium Development Group Gap Task Force. Delivering on the global partnership for achieving the millennium development goals: MDG Gap Task Force Report. New York: United Nations; 2008. http://www.un.org/ millenniumgoals/pdf/MDG\%20Gap\%20Task\%20Force\%20Report\%202008. pdf. Accessed 20 May 2016.

11. Global Initiative for Asthma-GINA. 2016. http://ginasthma.org/wp-content/ uploads/2016/04/wms-GINA-2016-main-report-final.pdf. Accessed 20 May 2016.

12. Global Initiative for Chronic Obstructive Lung Disease. 2016. http:// goldcopd.org/global-strategy-diagnosis-management-prevention-copd2016/. Accessed 20 May 2016.

13. WHO Model Lists of Essential Medicines. 2015. http://www.who.int/ medicines/publications/essentialmedicines/EML_2015_FINAL_amended_ NOV2015.pdf?ua=1. Accessed 11 Jan 2017.

14. Ministry of Health Republic of Uganda hospital categories. 2017. http:// www.health.go.ug/hospitals. Accessed 11 Nov 2017.

15. UBOS. Uganda National Household Survey 2016/2017. 2017. http://www ubos.org/onlinefiles/uploads/ubos/pdf\%20documents/UNHS_VI_2017_ Version_I_\%2027th_September_2017.pdf. Accessed 13 Nov 2017.

16. National Drug Authority (Uganda). Drug Inspectorate Services Department; 2017. http://nda.or.ug/ug/smenu/6/Drug-Inspectorate-ServicesDepartmenthtml. Accessed 11 Jan 2017.

17. Kibirige D, Atuhe D, Kampiire L, Kiggundu D, Donggo P, Nabbaale J, et al. Access to medicines and diagnostic tests integral in the management of 
diabetes mellitus and cardiovascular diseases in Uganda: insights from the ACCODAD study. Int J Equity Health. 2017;16:154.

18. WHO. World Health Organization, Health Action International. Measuring medicine prices, availability, affordability and price components 2nd edition. 2008. Available: http://www.who.int/medicines/areas/access/OMS_ Medicine_prices.pdf. Accessed 26 Dec 2014.

19. WHO. Management Sciences for Health. International Drug Price Indicator Guide. 2012. Available: http://apps.who.int/medicinedocs/documents/ s20208en/s20208en.pdf. Accessed 27 Dec 2014.

20. Ministry of Public Service, Republic of Uganda salary structure FY 2015-16 Primary school teachers. 2016. http://www.gou.go.ug/ministry/ministrypublic-service. Accessed 11 Jan 2017.

21. Cameron A, Ewen M, Ross-Degnan D, Ball D, Laing R. Medicine prices, availability, and aff ordability in 36 developing and middle-income countries: a secondary analysis. Lancet. 2009:373:240-9.

22. Mendis S, Fukino K, Cameron A, Laing R, Filipe-Jr A, Khatib O, et al. The availability and affordability of selected essential medicines for chronic diseases in six low- and middle-income countries. Bull World Health Organ. 2007:85:279-88.

23. Vialle-Valentin C, Serumaga B, Wagner A, Ross-Degnan D. Evidence on access to medicines for chronic diseases from household surveys in five low- and middle-income countries. Health Policy Plan. 2015;30:1044-52.

24. Medicine price monitor for Uganda. No. 12. 2014. http://apps.who.int/ medicinedocs/documents/s22316en/s22316en.pdf. Accessed 16 Mar 2017.

25. Medicine price monitor for Uganda. No. 13. 2015. http://apps.who.int/ medicinedocs/documents/s22317en/s22317en.pdf. Accessed 16 Mar 2017.

26. Ministry of Health, Republic of Uganda. Essential Medicines and Health Supplies List for Uganda (EMHSLU). 2012. http://www.health.go.ug/docs/_ EMHSL_2012.pdf. Accessed 15 Mar 2017.

27. Kotwani A. Availability, price and affordability of asthma medicines in five Indian states. Int J Tuberc Lung Dis. 2009;13(5):574-9.

\section{Submit your next manuscript to BioMed Central and we will help you at every step:}

- We accept pre-submission inquiries

- Our selector tool helps you to find the most relevant journal

- We provide round the clock customer support

- Convenient online submission

- Thorough peer review

- Inclusion in PubMed and all major indexing services

- Maximum visibility for your research

Submit your manuscript at www.biomedcentral.com/submit 